\title{
The color collocation of product packaging and the upgrade of brand culture
}

\author{
Xu Chong ${ }^{1, a}$ \\ ${ }^{1}$ Jiangxi college of foreign studies,NanChang,330099, China \\ axuchong@yeah.net
}

\begin{abstract}
Keywords: Color system collocation; Product packaging; Brand culture; Brand promotion; Influence
\end{abstract} research.

\begin{abstract}
With the increasingly fierce market competition and the rapid development of modern enterprises, enterprises are changing from a single product to their own unique brand image business model. The new technology enterprises constantly and increasingly improve the processing technology to improve the productivity of enterprises and brand promotion, but also in promoting the enterprise marketing strategy, is the added value to online and offline sales and advertising products and services to increase. So as to increase the sales of products and establish a good image of the enterprise. The packaging of the product has become an important factor in this matter. It is closely related to the sales of the product. And the use of color in the packaging is one of the important measures for the packaging design of good and bad. Greatly affect the competitiveness of the market. This article from the packaging color of the psychological packaging and packaging color of the marketing to discuss. The role of color in the packaging design is particularly important, it can even a large extent determine whether the goods sold or not. In modern society, the packaging of the application of color image, an important role in the process of circulation of goods to consumers will produce xianshengduoren. The depth and breadth of the market competition, the sensitivity of persistence is unprecedented, intense market competition and promote the development of production and consumption, while promoting the corporate marketing strategy inevitably updates, including packaging, of course be placed in an important position. Color application of human nature, rationality directly lead to the color of the personality is bound to strengthen the visual impact of the packaging, the role of promotion, greatly improve the ability of the market competition of its products.
\end{abstract}

\section{Introduction}

With the development of modern society, now people all the time and dealt with the goods, commodities have been deeply penetrated into people's life, the pursuit of fashion, shopping has become a trend and habits. The details of goods from packaging to sales to service all reflect people to pursue high quality of life, when people go to the supermarket to buy goods, make their goods caused by the desire of consumers to buy more is to consider the color design of packaging. Packaging is a powerful weapon in the communication between the manufacturer and the buyer. Imagine that consumers buy goods directly to see the image of the packaging. Or let the goods do advertising signs, especially the color packaging easier to attract the attention of consumers, there is a people's visual research shows that in a series of elements of products: trademarks, graphics, text, color. Color is the most direct people to make a direct stimulus to stimulate the purchase desire of consumers. Color in the packaging design of the role of other factors can not be compared. Color matching harmony can produce a strong visual impact[1], causing people's attention and direct reflection. Reveals the theme of the packaging, strengthen the impression. Make a deep impression on people. Both to achieve the enjoyment of the United States can also be able to pass out the information of this product. Therefore, the study of the use of packaging color for the sale of goods and the brand has a significant meaning. The following is the focus of analysis. The packaging of goods reflects the development level of society, and the general trend of packaging design is from complex to simple. In today's era of mass 
production and mass sales, modern packaging is the best bridge between producers and consumers. Because the packaging and consumers to meet directly, compared to other ads, it is easier to attract the attention of consumers. For human visual aspects of the study shows that in all the factors that constitute the product packaging, color can be the earliest and most pleasant to touch people's reaction, directly stimulate the consumer's desire to buy. So it has important significance to study the color of packaging. In packaging design, the color of the mix to consider the color of the psychological and social factors. Such as: the psychological reaction of color, and the symbolic, the color of the pleasant, the color of the series design and other issues. The processing of these problems will directly affect the sales of goods, therefore, should attract the attention of designers.

\section{The characteristics and psychological problems of packaging color}

An overview of the characteristics and psychological problems of packaging color. Now on the market of commodity packaging color most tend to be of high purity color, bright colors and collocation colors make the consumer's attention has been pay attention to. Basically in red, orange, blue, green, yellow, pink and so on in the color matching. Color will produce a wide range of feelings to people, science shows that in people's normal visual perception, for different colors will produce different imagination and feeling. People can find their own favorite color from the colorful color to their own identity. Color sense of space, the color of the weight, the color of the character, the color of the temperament and so on will be felt by the human personality. In three the properties of color, color can be divided into warm and cool colors of. Warm color to give warmth. Warm, positive, good feeling. The cool colors give people feel distant quiet strict quality. Orange is the color that the public can accept, because it symbolizes the positive, the vitality, the hope, the innovation and so on the psychological feeling. Red passion, passion, lively and so on. So red is one of the most enduring colors in the world, and it is always a popular color[2]. Yellow gives people a sense of clarity, comfort, ease and pleasure, wealth and authority. Green with a fresh, vibrant, peaceful, natural feeling. Blue gives a quiet, calm, strict psychological feelings. Gray is the most moderate color, but it gives people with advanced, simple, long the feeling of humility. General food packaging with warm food series, usually the main colors are red, yellow, green and pink, because the warm tone can stimulate the appetite, to give people a warm feeling of closeness. In addition to the sweet and pleasant taste. For example, everyone as everyone knows old godmother sauce series, are taken to transfer the red packaging design, product features spicy, see packaging people know its function to stimulate the appetite. Red is also used the world famous brand Coca-Cola carbonated beverage packaging, make people warm, passion, enthusiasm to notice the feeling of commodity. At the same time the red packaging can be the first to stimulate the eye of consumers, to achieve visual impact, resulting in the first impression of a profound effect. Liquor is generally a big red is mainly yellow, in order to increase the grade of products. Also meet the people in the festival to give relatives and friends of the happy feeling. Cakes with golden yellow, light yellow, yellow to give people a fresh aroma Xiren feeling. For example, Shenzhen Kingdee Xuan cakes its packaging color is light yellow to golden yellow and harmonious collocation, make the food delicious feeling. Fruit food or beverage with yellow, orange, yellow and other colors of nature, it is the first to highlight the natural fresh food. Second it stimulates people's taste, refreshing thirst. Let people have the vitality of the sun, the sense of objective upward, at this time the purchase desire of consumer psychology. For example, United's Orangeade fruit beverage series. The advertising language can drink fruit drink. In addition to the color of its packaging mainly orange, but also to the consumer for the products of pure natural characteristics of the feeling. Tea flavored drinks are usually green, and give people a sense of the original taste of tea.

The effect of color matching on daily cosmetics. Daily cosmetics category of normal use of the main colors of its main colors are pink, light green, light blue, rose color, coffee, etc.. To highlight the warm and elegant temperament. The lady with light colored more, to show the lady fresh bright, young, soft and elegant image of youth. For example, the famous cosmetics brand L'OREAL's products L'OREAL series are generally mainly used in light green color packaging. This color for 
female consumers to produce a youthful feeling, the color of the product information is transmitted by the use of this product after the skin youthful and delicate, to reduce the light pattern, pay, vibrant feelings. Another example is Galen brand packaging embodies the characteristics of beautiful women, is the best interpretation of feminine woman. Compared with women's psychological favor. While the TJOY brand packaging color with pearl white, in order to highlight the female skin white with faint blush, pure hearted feeling. Let the female consumers have the impulse to buy. Men's products are widely used in dark, especially black and dark blue. The beauty of masculinity. For example, the famous international brand Dior series of men's skin care products is black as the main color, the man's fortitude and fashion. In addition, high lightness and color lively feeling, low lightness color has a sense of quiet. The color of men's brand is also becoming more and more trend and the development of sophisticated[3].

The packaging color should use. Not only to each other between color and color, in fact, there are also associated with the color of the match, the nature is a harmonious whole. The use of color should also be taken into account in the end suitable for what kind of crowd. Because people's physical, psychological, and internal emotions are a coordination of the whole, the color of the people is not only the psychological aspects of the psychological impact. If affect the function of the human body, together with the pulse of the beating blood circulation, causing different periods of nerve reflect, directly affect the cerebral cortex, heart rate and some other nervous system function. Which makes people reflect on the color of a whole? If you know which kind of color matching for the crowd, it will make buyers feel comfortable, consumers will buy this product. The use of color in the packaging of the elderly. Elderly people with age, all aspects of the physical mechanism of occurrence of silent changes. Year by year in the past, the old people's understanding and memory gradually decreased, visual, auditory, tactile and other organs are declining, and the mind began to reflect the slow. Especially the decline in visual acuity, many elderly people in not near distance are very difficult to see the packaging to bring them visual and psychological feelings, psychological factors of the elderly will affect the body with the change. The elderly because rarely participate in social communication, and now the children of the elderly with little communication, develop the elderly autistic, self-esteem Ziqi, psychological vulnerability, present day dead. All of these will adversely affect the physical and mental health. Therefore, the use of bright colors in the elderly supplies packaging, but also can make the elderly with a positive and optimistic attitude to face life. Let sorrow be far away. For a flower love stay at home for the elderly are most receptive to red orange yellow green blue white. Because it can be associated with the spring, the wheat field, the sea and other natural things. Such as gold partner. One of the largest health care products companies in china. Its packaging color is yellow. Let old people see hope and light. Maintain a positive and optimistic attitude. And the weak constitution of the elderly should not choose black, purple, gray and other colors. Because the black will let the elderly have a feeling of death, but it is the grey color, not clear worries, will produce foreboding, purple mysterious atmosphere it is very heavy, make people feel very helpless.

\section{Classification of color matching}

Determine total tone. The overall feeling of packaging color is gorgeous or simple, are all depends on the total color of the packaging color. The basic properties of the total color hue, lightness and purity according to a specific embodiment of color. As bright, dark, bright, grey, cold, weak, soft, emphasis on training, hard reset, etc.. In addition to hue, brightness, color purity, size is an important factor which directly affects the tone. Color matching first considers the arrangement of large area color, large area of color in the packaging display has a long range of visual effects. In addition, in the color contrast is too strong, can not change the hue, lightness and purity, and expand or narrow one color area to reconcile. Visual perception is the definition of the level of color matching. Good visual recognition is very important in the design of visual communication, such as packaging, advertising, etc.. On the one hand, depending on the degree of recognition of the color itself, on the other hand to see the contrast between the colors. Its principle and method in advertising design also made a 
detailed introduction, can refer to its content, used to carry out the color design of packaging and decoration. Stressed that the color is the key color in the total color, is the area of factors and visual recognition with the use of color. General requirements higher than the surrounding color brightness and the degree, in the area is less than the surrounding color, otherwise not to emphasize. The use of interval color refers to the other colors in the middle of a strong contrast between the different colors, such as interval or for sharing, you can enhance coordination, weakening contrast. The color itself is neutral black, white, grey, gold and silver. Such as the use of color interval, interval requirements with the separated color difference in hue, lightness and purity. Gradually layer is the use of color, hue, lightness, gradually change, the purity can be gradually changes. Gradually layer color has a harmonious and rich color effect, in the packaging of color processing in the use of more. Different from the strong contrast color palette, this is the area of similar hue lightness compared with color, and this color has a strong visual effect, which has the advertisement. This is not directly mimic the content of color features, but also in accordance with the common understanding of the vast number of consumers to apply the concept of a card as a concept of color. Mainly used for the performance of some kind of spiritual attribute of the product or the performance of a certain brand idea. Such as the packaging of Chinese cigarettes on the selection of a symbol of the Chinese nation's color - red[4].

Contrast color design. Color matching is a knowledge, it is in the art design of the position in the end how important a design work, generally contains three elements: color, image, text. These three elements, the color is more important. People are very sensitive to color, when they first contact a design work, the first to grab their attention, is the color of the work; followed by the image of the work; the last is the text. The designer most easily through the color to express his ideas, and as a designer, you must know the function of color and refinement. Color a lot of learning involved, it includes optics, aesthetics, psychology and folklore etc.. Psychologists have put forward many theories on the relationship between color and human mind in recent years. They pointed out that has a certain symbolic significance each kind of color, when exposed to a color vision, the brain will receive payment of color signals, real-time image, such as red symbolizes passion, so people will see red mood; see blue symbolizes the reason, it will make people calm down. Experienced designers, often can skillfully use the color, and then arouse people to carry on the Psychological Association, so as to achieve their design objectives. The contrast color is in the hue ring relative to the color, because of our vision, in the monochrome environment requires the visual contrast color balance. The contrast of color can arouse the excitement of our vision, easy to stimulate, fresh, lively, vivid and other visual impression. In contrast color, according to the physical properties of color, there will be a contrast method contrast of hue and brightness contrast and comparison of different purity. Need to pay attention to the following issues in the design of the contrast color: (1) as far as possible the use of the relationship between the processing of color, to effectively grasp the color of the main tone, and make the main color and product attributes and creative ideas coincide; (2) in the case of increasing color factors, to maintain the order and integrity of the design elements. Here is also mentioned that since the emergence of computer graphics software, the computer has become the most faithful partner of designers. Looking at the designer's hands on the keyboard fast jump, the design of the computer screen moments of change, colorful scene, and the scene is really good. Undoubtedly, the computer graphics software makes the design work more efficient and convenient, the designer can quickly put something specific in mind imagine, can make a variety of effects, designers can play in space also increases accordingly. However, in the computer applications at the same time, we cannot deny the fact that the less humanized design in the part of more and more, increasing the proportion of the computer design, works seem less emotional, lack of human touch. Some designers rely too much on the computer, the design for the customer, Xiangyebuxiang, only in the computer to change the color of a and a, a look can be. Strictly speaking, these are not the designers, they completely ignore the most important part of the design: the brain's thinking. The computer can do the image very beautifully, but in the final analysis, it is only the material which itself has re presents it. If the designer, just left a lot of information to pick the right choice, and then made a piece of work put all sorts of things together, it works and what design art? The yellow, the green, why put in there? What 
is to express? No one bother. Because of this kind of color design is not human nature, it is also very difficult to arouse the audience's sympathy and recognition.

People oriented in color matching of packaging. Color is not only related to the display of goods, and different colors can make people have different feelings and associations, the use of color, there is a question of whether or not pleasant. The body includes physical, mental, emotional and spiritual, is a harmonious whole, affect the color of human body will be involved in all aspects, such as the impact of the functions of the human body, improve blood circulation; muscle tension caused by the reaction in different degree; effect of cerebral cortex, heart rate, respiration and other autonomic nervous system function thus, people in the aesthetic and emotional reaction. Therefore, if some items can directly reflect the characteristics in packaging design, but also with the buyers achieve the collision and the soul, to make the buyers feel comfortable, so this kind of commodities is likely to become the preferred commodity buyers. In the reflection of commodity quality, "according to the inherent color attributes of goods or commodities, take vivid color to the buyers of goods recalled, the basic content, the characteristics of commodity judgment" is an important means for the design of color, cakes food packing with yellow color, fragrance symbol; tea or coffee, whisky, beer and other beverages with brown, feel rich; with orange yellow Fresh Carrot Juice packaging, milk white milk, toothpaste skin generally white, lemon yellow lemon shampoo packaging design in cosmetics...... These use of color in the color of the product itself, the color reproduction of the way, the most can give people with the object class of association, make people in the physiological and psychological generation coordination, and produce purchase desire. Packaging color design should also be based on the different customs of consumers, grade requirements and age, gender differences, emphasizing the color of the pleasant. In the Tibet area, the white symbolizes holiness, in most of the domestic white is the funeral of the use of color, when in use should be considered regional; male, older people should pursue product packaging, color stable, dignified, tasteful; female, young people are packing, color should be the pursuit of romance, warm and lively; children's products packaging, color is bright, should focus on jumping, lively and bright[5].

\section{Summary}

From the psychological knowledge of packaging color to the color of people from the point of view of the analysis of the design of color marketing. The color of packaging and its own characteristics, the characteristics of the people, the characteristics of society is closely linked. Only the first understanding of the inherent characteristics of the color, in the understanding of the appropriate crowd, to the color of marketing to achieve the purpose of improving the sales of goods, improve the productivity of enterprises.

\section{References}

[1] Han Xuehong. The creative elements in packaging design from the perspective of cultural and creative industries -- a case study of food packaging [J]. popular literature and art. 2015 (07).

[2] Li Qinglong. Packaging creative industries and the integration of the product development [J]. Shanghai packaging. 2014 (12).

[3] Wang Lanzhen. Packaging design color vision for the United States [J]. packaging engineering. 2014 (16).

[4] Liu Liwei. On the meaning of packaging color vision to convey the meaning of the words [J]. packaging engineering. 2014 (12).

[5] song Wenyan. On the era of perceptual consumption psychology is applied in [J]. China packaging industry. 2014 (08). 